\title{
"Pulley type" countertraction for colonic endoscopic submucosal dissection of laterally spreading tumors involving a diverticulum
}

Colonic endoscopic submucosal dissection (ESD) for tumors involving a diverticulum has a high risk of causing perforation, owing to the lack of a proper muscle layer in the diverticulum [1,2]. In addition, it is often difficult for endoscopists to obtain a clear field of view in the diverticulum [3].

The advantage of "pulley type" countertraction is that continuous traction can be performed regardless of gravity. In addition, countertraction can be performed with a simple tool made with dental floss and ordinary clips.

The patient was an 80-year-old man. Colonoscopy revealed a $20-\mathrm{mm}$ granular laterally spreading tumor (LST) involving

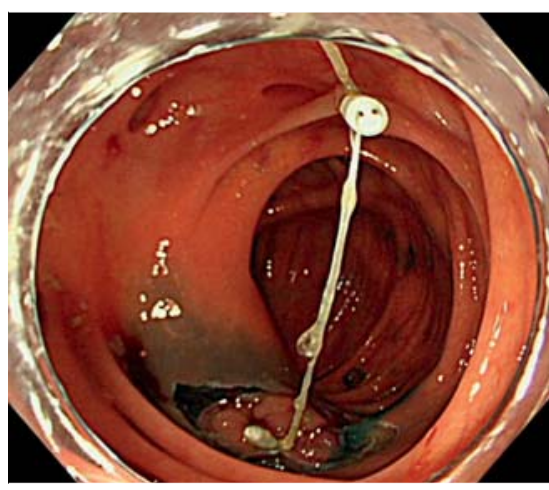

- Fig. 1 Setting up the dental floss and clips to work as a pulley.

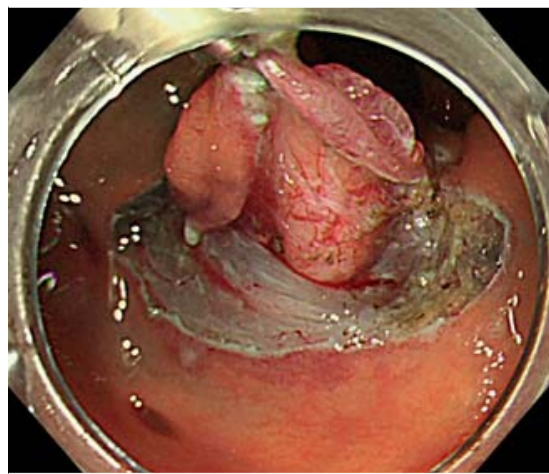

- Fig. 2 The countertraction method created a clear field of view while pulling the lesion.

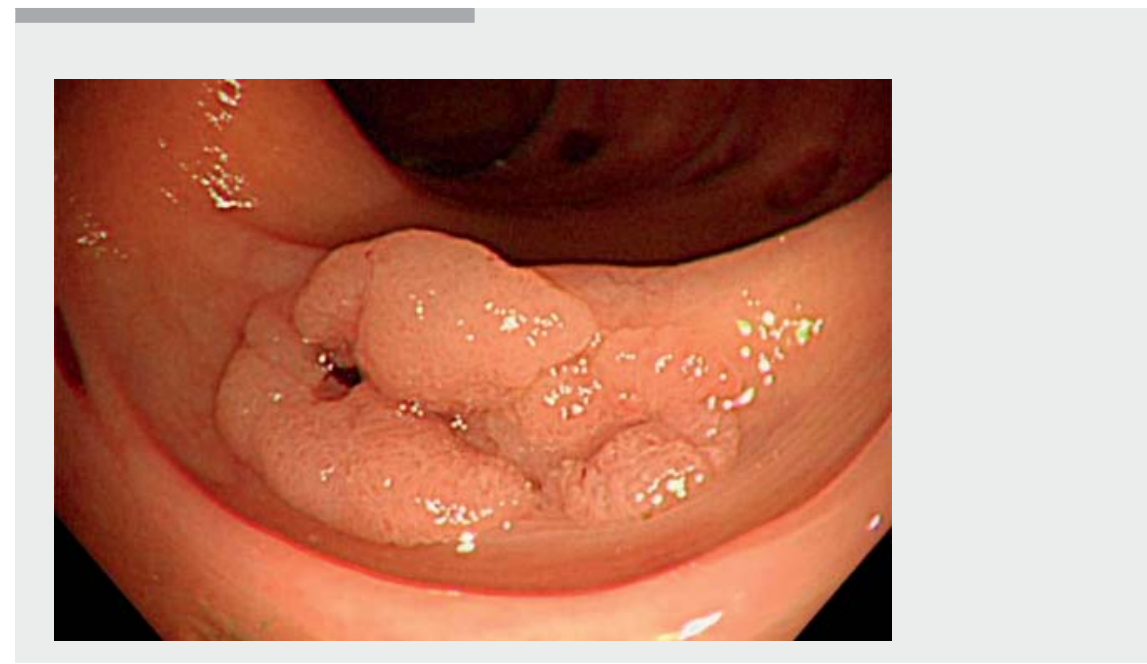

$\checkmark$ Video 1 "Pulley type" countertraction using dental floss and clips for colonic endoscopic submucosal dissection of a laterally spreading tumor involving a diverticulum. Text 1. LST involving a diverticulum. Text 2. Circumferential mucosal incision. Text 3. "Pulley type" countertraction.

a diverticulum in the ascending colon $(\triangleright$ Video 1$)$. We first made a circumferential mucosal incision using a dual knife (Olympus, Tokyo, Japan) after injecting a glycerol mixture. Next, we resected the lesion from the anal side to the diverticulum as far as possible, and placed dental floss and a clip on the anal side of the lesion. Then, we placed a second clip on

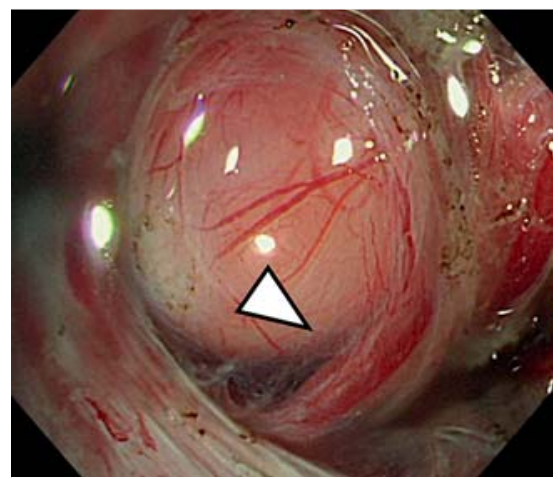

- Fig. 3 A clear field of view was achieved, and an incision was made while avoiding the perforator branch that causes bleeding of the diverticulum (black arrowhead). the contralateral side of the lesion to enable the dental floss to work as a pulley ( $\vee$ Fig. 1). This countertraction method created a clear field of view while pulling the lesion into the diverticulum, and enabled ESD to be performed safely and easily ( Fig. 2). We were able to make an incision with a clear field of view, while avoiding the perforator branch that causes bleeding of the diverticulum ( Fig.3), and en bloc resection was

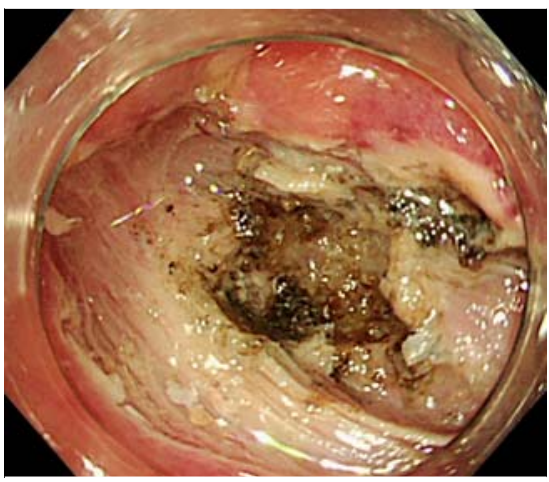

Fig. 4 En bloc resection was completed without any complications. 


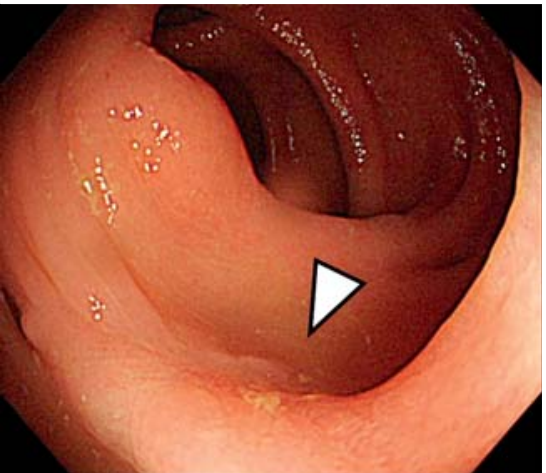

- Fig. 5 Colonoscopy 3 months after ESD demonstrated that the diverticulum had disappeared and had formed a scar (black arrowhead) .

completed without any complications ( Fig.4). Finally, the diverticulum was closed using the clips. Pathological analysis indicated a high-grade tubular adenoma with free margins. Colonoscopy 3 months after ESD demonstrated that the diverticulum had disappeared and had formed a scar ( $\mathbf{F i g . 5}$ ).

Our case demonstrates that "pulley type" countertraction using dental floss and clips is a useful and safe method for ESD of LST involving a diverticulum.

\section{Competing interests}

The authors declare that they have no conflict of interest.

The authors

Hayato Yamaguchi ${ }^{1,2}$, Masakatsu Fukuzawa', Takashi Kawai $^{3}$, Yubu Matsue ${ }^{2}$, Takao Itoi $^{1}$

1 Department of Gastroenterology and Hepatology, Tokyo Medical University, Tokyo, Japan

2 Department of Gastroenterology and Hepatology, Tokyo Medical University Hachioji Medical Center, Tokyo, Japan

3 Endoscopy Center, Tokyo Medical University Hospital, Tokyo, Japan

\section{Corresponding author}

\section{Hayato Yamaguchi, MD, PhD}

Department of Gastroenterology and Hepatology, Tokyo Medical University, 6-7-1 Nishishinjuku, Shinjuku-ku, Tokyo 160-0023, Japan

Fax: +81-03-5381-6654

hayato10@tokyo-med.ac.jp

\section{Acknowledgments}

The authors thank medical editor $\mathrm{H}$. Popiel of the Department of International Medical Communications of Tokyo Medical University for editorial review of the Engish manuscript.

\section{References}

[1] Kim ES, Cho KB, Park KS et al. Factors predictive of perforation during endoscopic submucosal dissection for the treatment of colorectal tumors. Endoscopy 2011; 43: 573-578

[2] Sakamoto T, Abe S, Nakajima T et al. Complete removal of a colonic neoplasm extending into a diverticulum with hybrid endoscopic submucosal dissection-mucosal resection and endoscopic band ligation. Endoscopy 2015; 47: E295-E296

[3] Iwatsubo T, Uedo N, Yamasaki Y et al. Traction-assisted colorectal endoscopic submucosal dissection by use of clip and line for a neoplasm involving colonic diverticulum. VideoGIE 2017; 2: 337

\section{Bibliography}

DOI http://dx.doi.org/10.1055/a-1216-1740

Endoscopy International Open 2020; 08: E1183E1184

(c) Georg Thieme Verlag KG

Stuttgart · New York

eISSN 2196-9736 